\title{
Role of Vascular Alpha-2 Adrenoceptors in Regulating Lipid Mobilization from Human Adipose Tissue
}

\author{
Jean Galitzky, ${ }^{*}$ Max Lafontan, ${ }^{\star}$ Jörgen Nordenström, ${ }^{\star}$ and Peter Arner \\ *Institut National de la Santé et de la Recherche Médicale (Institut National de la Santé et de la Recherche Médicale U317), \\ Institut Louis Bugnard, CHU Rangueil, Faculté de Médecine, Bat L3, 31054 Toulouse Cedex, \\ France; and Departments of ${ }^{\ddagger}$ Surgery and ${ }^{\S}$ Research Center, Huddinge Hospital, S-14186 Huddinge, Sweden
}

\begin{abstract}
The role of alpha-2 adrenoceptors in lipid mobilization and blood flow was investigated in situ using microdialysis of subcutaneous adipose tissue in nonobese healthy subjects. The alpha-2 agonist clonidine caused dose-dependent biphasic response with increased glycerol levels at low clonidine concentrations and decreased glycerol levels at concentrations $>\mathbf{1 0}^{-7}$ mol/liter. Similar results were observed with epinephrine plus propranolol. Clonidine action was unaffected in the presence of labetalol (beta-/alpha-1 antagonist) but completely blunted by the presence of yohimbine (alpha- 2 antagonist). The pseudolipolytic effect of clonidine was significantly more pronounced in gluteal as compared with abdominal adipose tissue. When clonidine was added together with the vasodilating agents nitroprusside or hydralazine, the pseudolipolytic effect was abolished and a dose-dependent decrease in dialysate glycerol was observed at all clonidine concentrations $\left(10^{-10}-10^{-4} \mathrm{~mol} /\right.$ liter $)$. When ethanol was added to the perfusate to monitor blood flow, the escape of alcohol from the dialysate was accelerated by $30 \%$ with hydralazine or nitroprusside $(P<0.01)$ and $30 \%$ retarded $(P<0.05)$ by clonidine $\left(10^{-10} \mathrm{~mol} /\right.$ liter $)$. Thus, the results demonstrate an important role of blood flow for regulating lipid mobilization from adipose tissue in vivo. Alpha-2 adrenoceptor activation causes marked retention of lipids in adipose tissue due to vasoconstriction in combination with antilipoiysis. (J. Clin. Invest. 1993.91:1997-2003.) Key words: fat cell $\bullet$ catecholamines $\bullet$ microdialysis $\bullet$ lipolysis $\bullet$ clonidine $\bullet$ yohimbine
\end{abstract}

\section{Introduction}

It is now well established that lipid mobilization in human fat cells, which operates through hydrolysis of triacylglycerols into free fatty acids and glycerol (lipolysis), is essentially under control of catecholamines. Human adipocytes possess both betaand alpha-2 adrenoceptors in the plasma membrane, which mediate opposite effects on the metabolism of this cell $(1,2)$. Alpha-2 adrenergic receptor stimulation by catecholamines promotes inhibition of lipolysis, whereas beta adrenergic recep-

Address correspondence and reprint requests to Dr. Peter Arner, Department of Medicine, Huddinge Hospital, S-14186 Huddinge, Sweden.

Received for publication 14 September 1993 and in revised form 3 December 1993.

J. Clin. Invest.

(C) The American Society for Clinical Investigation, Inc.

0021-9738/93/05/1997/07 \$2.00

Volume 91, May 1993, 1997-2003 tor activation mediates its stimulation (2-4). In vitro studies have shown that the balance between beta and alpha- 2 adrenoceptor activation controls the final lipolytic response induced by catecholamines in human adipocyte $(5,6)$. In vivo, induction of lipomobilization will depend on the activation of fat cell lipolysis by catecholamines but also on the changes induced in the vascular tone by these agents. Previous studies have revealed that in vivo lipolysis can be altered by the adrenergic effects on blood vessels which modify the microcirculation and thereby the blood flow in the adipose tissue (7). The alpha-2 receptors in adipose tissue may be of particular importance for lipid mobilization since they promote antilipolysis in fat cells and venous constriction $(5,7)$.

At present, most of the knowledge about catecholamine effects on human fat cell lipolysis has been obtained from in vitro studies or from measurements of the change in the bloodstream of the products of lipolysis ( nonesterified fatty acids and glycerol ). Both techniques only give limited information about what could occur in the in vivo conditions.

Recently a microdialysis method that allows in situ studies of catecholamine action on lipolysis in adipose tissue was developed and validated (8). With this technique it is possible to expose small areas of adipose tissue to adrenergic agents and avoid systemic effects of the drugs $(9,10)$. Using another recently developed technique to measure the escape of ethanol (added to the dialysis solvent) into the peripheral tissue it is possible to indirectly estimate blood flow in connection with microdialysis (11).

The role of alpha-2 adrenergic receptors for lipolysis and microcirculation was investigated in abdominal and gluteal adipose tissue in healthy male and female subjects. Microdialysis probes were implanted for the study of glycerol levels in interstitial space and escape of ethanol to this compartment under various pharmacological treatments.

It is demonstrated that the activation of alpha- 2 adrenoceptors with clonidine or epinephrine leads to a paradoxal increase in adipose tissue glycerol due to activation of vascular receptors of adipose tissue. This increase in glycerol was abolished when direct-acting vasodilators were added to the dialysis solvent. Then the antilipolytic effect of clonidine, which is linked to the stimulation of the alpha- 2 adrenoceptors component on human fat cells, was observed, indicative of a hitherto unrecognized role of vascular alpha-2 adrenoceptors in the regulation of lipid mobilization from adipose tissue.

\section{Methods}

Subjects. The experimental group was composed of 24 healthy, drugfree nonobese volunteers ( 8 men and 14 women). The age (mean \pm SEM) was $33.3 \pm 1.7$, and the body mass index $\left(\mathrm{kg} / \mathrm{m}^{2}\right)$ was $23.5 \pm 0.5$. The waist/hip ratio was $0.916 \pm 0.016$. They all undertook regular moderate exercise, but no one was involved in athletic perfor- 
mances. The subjects were investigated on one or two occasions. The study was approved by the Ethical Committee of the Karolinska Institute. The subjects were given a detailed description of the study and their consent was obtained.

Microdialysis probe. The microdialysis probe (Carnegie Medecin, Stockholm, Sweden) has been previously described in detail (12). Briefly, a dialysis tubing $(20 \times 0.5 \mathrm{~mm}, 20,000 \mathrm{~mol}$ wt cutoff) was glued to the end of a double-lumen steel cannula. The perfusion solvent enters the probe through the inner cannula, passes down to the tip of the probe, streams upward in the space between the inner cannula and the outer dialysis membrane, and leaves the probe through the outer cannula via a sidearm from which it is collected.

Experimental protocol. The experiments were performed at rest and were conducted as follows. The subjects were investigated in the supine position at 8 A.M. after an overnight fast. The dialysis probe was inserted percutaneously without anesthesia into the abdominal subcutaneous adipose tissue in a square $(10 \mathrm{~cm} \times 10 \mathrm{~cm})$ immediately to the right of the umbilicus or in the upper lateral part of the gluteal region. Depending upon the type of experiment, one to four probes were used in each occasion. The distance between each probe was always $30 \mathrm{~mm}$. The inlet tubing of the probe was connected to a microinjection pump (Carnegie Medecin) and was continuously perfused $(2.5 \mu \mathrm{l} / \mathrm{min}$ unless otherwise stated) with Ringer's solution; the composition of this solvent has recently been described (13). All the drugs used were added as sterile solutions to the ingoing perfusate. In each experiment, 10-rnin fractions (unless otherwise stated) of the outgoing dialysate were collected for glycerol analysis. The first three 10-min fractions were excluded, since previous experiments have shown that there was a transcient rise in ATP concentration in the outgoing dialysate during the first $30 \mathrm{~min}$ of dialysis, which is probably due to the initial trauma caused by the insertion of the dialysis probe into the adipose tissue (14). At the perfusion velocity currently used, the in vitro recovery for glycerol, determined as described previously (8), was $30 \%$. When adipose tissue was perfused with Ringer's solution alone, there was a constant glycerol level in the dialysate for at least $4 \mathrm{~h}$.

Analysis of glycerol. $25 \mu$ l of perfusate were obtained for the analysis of glycerol, using an automatic and computerized ultrasensitive kinetic bioluminescence assay of glycerol $(15,16)$. A luminescence analyzer (LKB-Wallac, Helsinki, Finland) was used for the assay.

Analysis of ethanol. $15 \mu \mathrm{l}$ of perfusate were obtained for an enzymatic determination of ethanol (17). A conventional spectrophotometer was used for the assay.

Materials. Adrenaline bitartrate came from Kabi AB (Stockholm, Sweden); clonidine hydrochloride from Boehringer Ingelheim (Ingelheim/Rhein, West Germany); hydralazine hydrochloride was from Ciba-Geigy (Basel, Switzerland) and sodium nitroprusside from Roche (Basel, Switzerland).

Statistical analysis. Values for glycerol are in general presented as a percentage of the baseline value because of the interindividual variations in baseline glycerol levels. However, all statistical comparisons were made on absolute values ( $\mu \mathrm{mol} /$ liter $)$; these values were distributed in a normal fashion. The coefficient of variance of the baseline glycerol level was $9 \%$ in gluteal and $10 \%$ in abdominal adipose tissue. The Student's paired $t$ test or ANOVA were used for determination of significance of the statistical comparisons.

\section{Results}

In order to evaluate the alpha- 2 adrenergic antilipolytic responsiveness in fat cells, the alpha- 2 agonist clonidine was perfused in situ at different concentrations $\left(10^{-10}-10^{-4} \mathrm{~mol} /\right.$ liter $)$ in two subcutaneous localizations (Fig. 1). The concentration of glycerol in the dialysate was increased by clonidine in both tissues at the lowest concentrations $\left(10^{-10} \mathrm{~mol} /\right.$ liter $)$. At higher concentrations $\left(10^{-9}-10^{-4} \mathrm{~mol} /\right.$ liter $)$ clonidine still rose dialysate glycerol in the gluteal region. On the contrary,

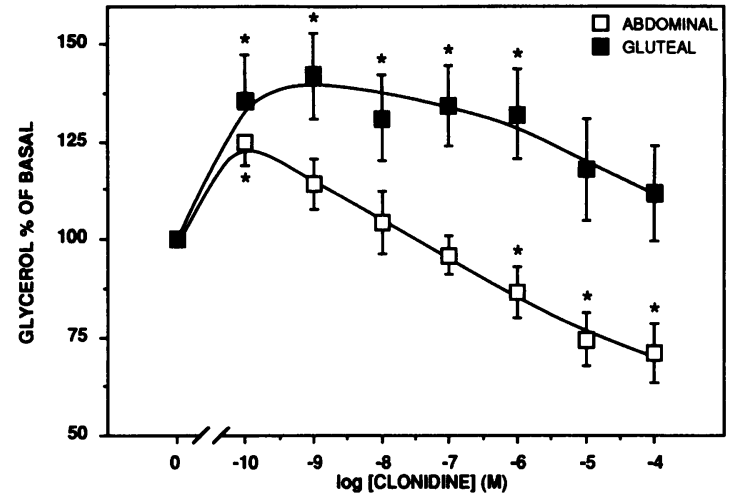

Figure 1. Effect of alpha-2 agonist stimulation on glycerol levels in dialysate from human subcutaneous adipose tissue. Two probes were implanted, one in the abdominal area and one in the gluteal area, and perfused with Ringer's solution $(2.5 \mu \mathrm{l} / \mathrm{min})$ alone for $30 \mathrm{~min}$. Then increasing concentrations of clonidine were added to the ingoing dialysis solvent every $30 \mathrm{~min}$. The perfusate was collected at 10min intervals. The average glycerol value in the first three fractions was calculated (basal), and clonidine values in each subsequent 30 min interval were combined to form a mean value and were expressed as a percentage of the baseline value. Values are mean \pm SEM from five men and seven women. Statistical calculations were performed on absolute values (i.e., $\mu \mathrm{mol} /$ liter of glycerol). ANOVA analysis of the data show that there was no sex difference, but found a statistical difference between the two adipose deposits $(F=5$ to 11$) .{ }^{*}$ Values statistically different from basal values at $P<0.05$ using paired $t$ test. The basal glycerol level was $68.3 \pm 14.2 \mu \mathrm{mol} /$ liter and $53.2 \pm 11.9$ $\mu \mathrm{mol} /$ liter in the abdominal and gluteal regions respectively.

clonidine decreased the concentration of glycerol in the dialysate at concentrations above $10^{-7} \mathrm{~mol} /$ liter in abdominal adipose tissue in dose-dependent fashion. ANOVA analysis of the clonidine effect in these two adipose tissue localizations demonstrated that there was no sex-related influence $(F<0.5)$ while a clear tissue-localization factor could be revealed $(F=5$ to 11$)$. The findings in Fig. 1 were somewhat surprising since, in previous microdialysis experiments on adipose tissue of five women, a dose-dependent decrease of the dialysate glycerol level using clonidine in concentrations ranging from $10^{-10}$ to $10^{-7} \mathrm{~mol} /$ liter was observed (9). However these women weighed significantly less than the female subjects in the present study (body mass index $20.4 \pm 0.3$ vs. $22.6 \pm 0.6 ; P<0.05$ ). In addition the probe was shorter $(10 \mathrm{~mm})$ and the perfusion speed higher $(5 \mu \mathrm{l} / \mathrm{min})$ than in the present study. These differences in body mass (and presumably in body fat) as well as in experimental procedures may explain the divergent results.

An effect, similar to the paradoxal one of clonidine, was also found when epinephrine was perfused in situ to tissue that was pretreated with $10^{-4} \mathrm{~mol} /$ liter of propranolol to block the beta adrenergic action and unmask the alpha action of the hormone. Fig. 2 shows that epinephrine caused a dose-dependent increase in the glycerol level in the microdialysate from gluteal fat deposits, while low epinephrine concentrations increased and high concentrations failed to promote any change in the glycerol level in abdominal tissue.

The mechanism of the paradoxal effect of clonidine on in situ lipolysis was explored in order to assess if its action was linked to alpha- 2 adrenoceptors. These experiments were per- 


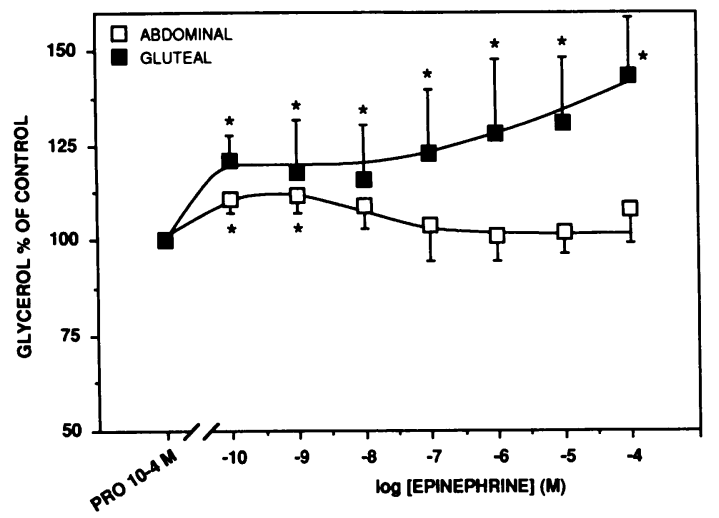

Figure 2. Effect of perfusion of epinephrine plus propranolol on glycerol levels in dialysate in human gluteal and abdominal adipose tissue. Two different probes were inserted in the same subject, one in the abdominal and the other in the gluteal area. They were perfused with Ringer's solution $(2.5 \mu \mathrm{l} / \mathrm{min})$ containing propranolol $\left(10^{-4}\right.$ $\mathrm{mol} /$ liter) for $30 \mathrm{~min}$. Then increasing concentrations of epinephrine were added to the ingoing dialysis solvent at 30 -min intervals. Perfusate was collected at 10 -min intervals. The three infusion periods prior to epinephrine were used to obtain baseline glycerol concentration (PRO $10^{-4} \mathrm{M}$ ), which was $112.1 \pm 12.0 \mu \mathrm{mol} /$ liter in abdominal and $81.3 \pm 6.5 \mu \mathrm{mol} /$ liter in the gluteal region and set at $100 \%$. Then, determination on three 10-min intervals were performed for each epinephrine concentration as described in legends to Fig. 1. Values are means \pm SEM from five experiments. ${ }^{*}$ Values statistically different from the basal values at $P<0.05$ using paired $t$ test on absolute values for glycerol.

formed only in the gluteal region where the clonidine effect was the strongest. When increasing concentrations of clonidine were infused in gluteal adipose tissue that had been preexposed to the beta-/alpha- 1 selective antagonist labetalol $\left(10^{-4} \mathrm{~mol}\right.$ /

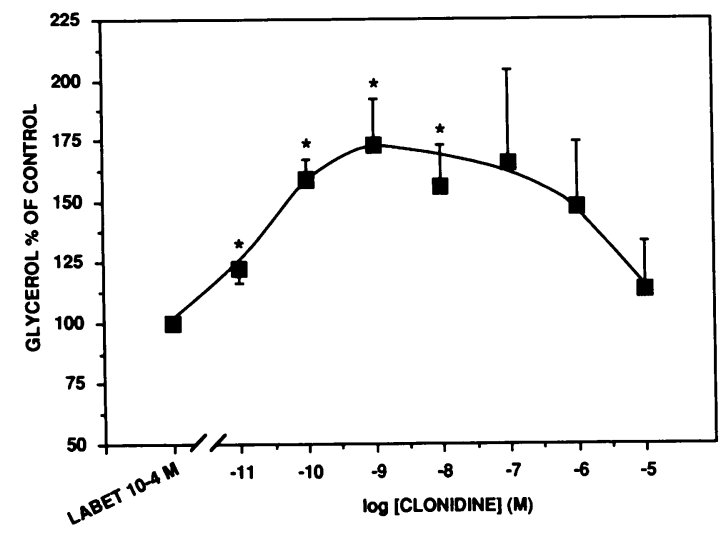

Figure 3. Effect of alpha 1/beta-adrenoceptor blockade with labetalol on clonidine-induced changes in glycerol levels in dialysate from gluteal subcutaneous adipose tissue. After insertion in the gluteal region the probe was perfused with Ringer's solution $(2.5 \mu \mathrm{l} / \mathrm{min})$ containing labetalol ( $10^{-4} \mathrm{~mol} /$ liter $)$ for $30 \mathrm{~min}$. Then, increasing concentrations of clonidine were added to the ingoing dialysis solvent every $30 \mathrm{~min}$ and dialysate was collected every $10 \mathrm{~min}$. The three initial infusion periods of $10 \mathrm{~min}$ were used for determining the basal glycerol level (LABET $10^{-4} \mathrm{M}$ ), which was $22.3 \pm 3.3 \mu \mathrm{mol} /$ liter. The clonidine effect was calculated as described in legend to Fig. 1. Values are means \pm SEM from six experiments. *Values statistically different from basal values at $P<0.05$ using paired $t$ test on absolute values for glycerol. liter), the clonidine increment of glycerol concentration in the dialysate remained unchanged (Fig. 3). Similarly, the nonselective beta adrenoceptor antagonist propanolol $\left(10^{-4} \mathrm{~mol} /\right.$ liter) was unable to antagonize the clonidine effect (Fig. 4). On the contrary, when adipose tissue was preexposed to the selective alpha-2-adrenoceptor antagonist yohimbine $\left(10^{-4} \mathrm{~mol} /\right.$ liter) in combination with propranolol the increment in the glycerol level in the dialysate induced by increasing concentration of clonidine was fully abolished.

To find out whether vascular events were involved in the control of clonidine-induced changes of glycerol in the dialysate, clonidine infusions were performed in gluteal tissue after administration of compounds known to depress the vascular tone, such as hydralazine and nitroprusside. Pretreatment of adipose tissue with either hydralazine or nitroprusside counteracted the increasing effect of the alpha-2 agonist on the glycerol concentration (Fig. 5). Instead, clonidine caused an expected dose-dependent decrease in the glycerol level of adipose tissue.

In order to study microcirculation in adipose tissue, the ethanol method for indirect monitoring of blood flow changes in skeletal muscle (11) was applied to human adipose tissue (Fig. 6). Upon initiation of $5.6 \mathrm{mmol} /$ liter of ethanol to Ringer's solution, the concentration of ethanol in the collected dialysate gradually increased over the first $20 \mathrm{~min}$ and stabilized thereafter. The same pattern of increase was also seen when the ethanol concentration in the perfusion solvent was increased to $53 \mathrm{mmol} /$ liter. In order to compare ethanol kinetics at the two different alcohol concentrations, we calculated the data as outflow/inflow ratios, i.e., concentration of ethanol in the outgoing dialysate divided by the concentration

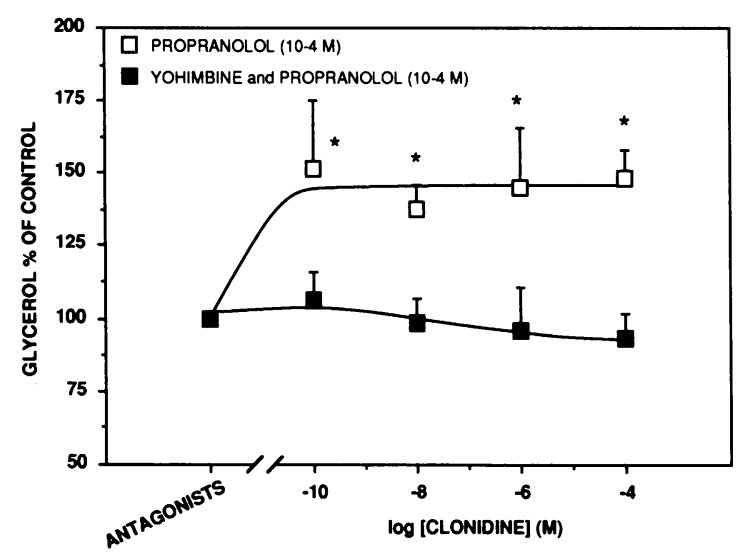

Figure 4. Effect of alpha-2 blockade and/or beta-adrenoceptor blockade on clonidine induced changes in the glycerol level of gluteal subcutaneous adipose tissue. The experiments were conducted as described in Fig. 2. Two probes were implanted in the gluteal area at a distance of $30 \mathrm{~mm}$ and perfused for 30 min with Ringer's solution ( $2.5 \mu \mathrm{l} / \mathrm{min}$ ) containing either propranolol $\left(10^{-4} \mathrm{~mol} /\right.$ liter $)$ or yohimbine + propranolol $\left(10^{-4} \mathrm{~mol} /\right.$ liter $)$, and microdialysate was collected at 10 -min intervals. Then increasing concentrations of clonidine were added to the ingoing dialysis solvent every $30 \mathrm{~min}$. The three initial 10-min periods were used for the determination of basal glycerol value which was $23.6 \pm 8.8 \mu \mathrm{mol} /$ liter for propranolol and $32.1 \pm 5.8 \mu \mathrm{mol} /$ liter for propranolol + yohimbine. Values are obtained and statistically compared as described in Fig. 1 and are means \pm SEM from three experiments. *Values statistically different from basal values at $P<0.05$ using paired $t$ test. 


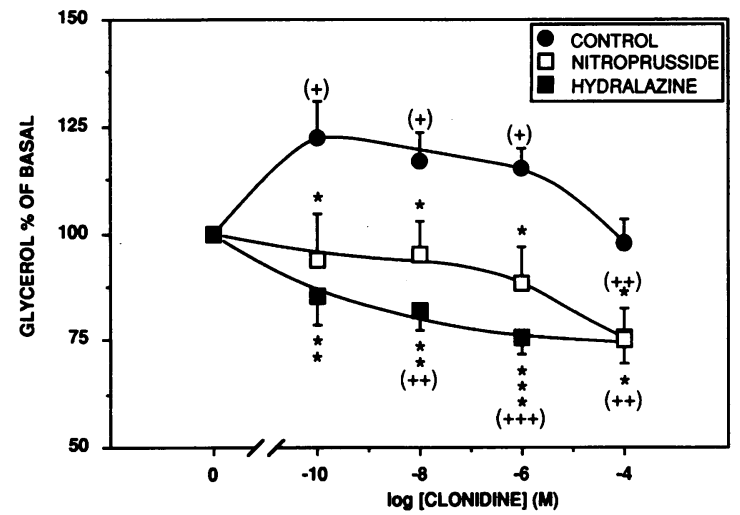

Figure 5. Effect of direct-acting vasodilators on clonidine-induced changes in the glycerol level of gluteal subcutaneous adipose tissue. Three probes were implanted in the gluteal area at a distance of 30 $\mathrm{mm}$ and perfused for $30 \mathrm{~min}$ with Ringer's solution $(2.5 \mu \mathrm{l} / \mathrm{min})$ containing either hydralazine $(0.125 \mathrm{~g} /$ liter $)$ or nitroprusside $(1.25$ $\mathrm{g} /$ liter). Then increasing concentrations of clonidine were added to the ingoing dialysis solvent at 30 -min intervals. Dialysate was collected at 10 -min intervals. See legends to Fig. 1 and 2 for further details. The basal glycerol value was $23.5 \pm 3.1 \mu \mathrm{mol} /$ liter for hydralazine and $14.7 \pm 1.9 \mu \mathrm{mol} /$ liter for nitroprusside. Values are mean $\pm \mathrm{SEM}$ from eight men and women. $(+)$ values statistically different from basal values at $P<0.05$ using paired $t$ test, $(++) P<0.01$ and $(+++)$ $P<0.001$. ${ }^{*}$ Values statistically different from control values at $P$ $<0.05$ using paired $t$ test, ${ }^{* *} P<0.01$ and ${ }^{* * *} P<0.001$

in the perfusion solution. These kinetics were almost identical, and the ethanol ratio was stabilized at about $70 \%$, using the high and low ethanol concentration. As discussed earlier (11), these findings not only are important from a methodological standpoint but also suggest that ethanol per se does not alter blood flow in adipose tissue.

The possible influence of ethanol on the adipose tissue glycerol level was investigated in six subjects. Abdominal adipose tissue was microdialized during $3 \mathrm{~h}$ with Ringer's as in the previous experiments, but the collection period was $15 \mathrm{~min}$. In addition a shorter dialysis probe $(10 \mathrm{~mm})$ was used (9). Ethanol ( $50 \mathrm{mmol} /$ liter) was added to the Ringer's solution during the second hour period. The glycerol levels $(\mu \mathrm{mol} / \mathrm{liter})$ in the 12 subsequent microdialysis fractions were $13.6 \pm 1.0$, $14.8 \pm 1.1,13.1 \pm 0.7,14.3 \pm 0.6,15.0 \pm 0.8,16.7 \pm 0.4,14.3 \pm 0.3$, $13.0 \pm 0.7,13.5 \pm 0.1,11.4 \pm 0.2,15.2 \pm 0.3$, and $15.1 \pm 0.1$. These values did not show a statistically significant variation. This strongly suggests that ethanol, in the concentrations used in the present experiments, has no effect on lipolysis in adipose tissue.

Using the ethanol method the effects of clonidine, nepresol, and nitroprusside on adipose tissue blood flow were investigated (Fig. 7). Addition of nitroprusside ( $1.25 \mathrm{~g} /$ liter) to the ethanol supplemented perfusion solvent decreased outflow/inflow ethanol ratio significantly from about $80 \%$ to about $60 \%$. When nitroprusside was removed from the perfusion medium the outflow/inflow ratio increased significantly. These data suggest that nitroprusside can accelerate the escape of ethanol from the dialysis solvent into the tissue surrounding the microdialysis probe because of a stimulation of blood flow in that tissue. Similar results were obtained with hydralazine $(0.125$ $\mathrm{g} /$ liter), which caused a significant and reversible decrease in the outflow/inflow ratio of ethanol from about 75 to $65 \%$. On the other hand, clonidine $\left(10^{-10} \mathrm{mmol} /\right.$ liter $)$ which promoted a marked rise in dialysate glycerol in the lipolysis experiments, increased significantly the outflow/inflow ratio of ethanol from about 65 to $80 \%$. This ratio diminished significantly when clonidine was removed from the perfusion solvent. The latter findings indicate that clonidine retarded the escape of ethanol from the dialysis solvent due to an inhibitory effect on blood flow. It should be noted that the outflow/inflow ratio before the addition of active drugs was lower in the clonidine experiment than in the vasodilator experiment. This is due to the lower perfusion speed $(1.5 \mu \mathrm{l} / \mathrm{min})$ in the former experiments.

\section{Discussion}

In the present study the importance of the vascular tone for lipid mobilization has been studied for the first time in intact adipose tissue. The alpha- 2 adrenergic regulation of lipid mobilization and microcirculation has been investigated in situ in both gluteal and abdominal adipose tissue of men and women. This was performed by, first, continuously monitoring the glycerol levels in the intracellular fluid of the subcutaneous adipose tissues before and after local exposure of fat cells to adrenergic agents by means of the microdialysis technique and, second, using the latter technique for investigating the escape of eth-
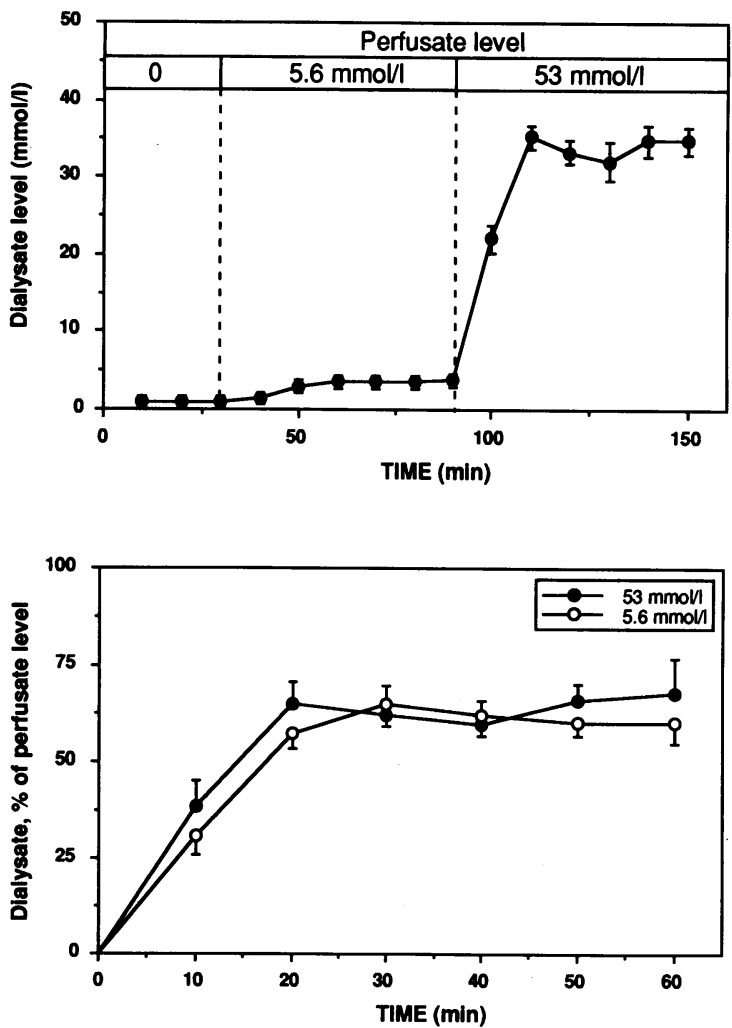

Figure 6. Ethanol concentrations during microdialysis. Abdominal subcutaneous adipose tissue was dialyzed with Ringer's solution ( 2.5 $\mu \mathrm{l} / \mathrm{min})$. During the periods of time indicated in the upper graph, ethanol was added at two different concentrations ( 5.6 and 53 $\mathrm{mmol} /$ liter) to the perfusion solvent, and the alcohol concentration was determined in the outgoing dialysate, which was collected at 10 min-intervals ( upper graph). The lower graph shows the ratio in percentage of the ethanol concentration in the dialysate vs. the perfusate. Values are mean \pm SEM of four separate experiments. 

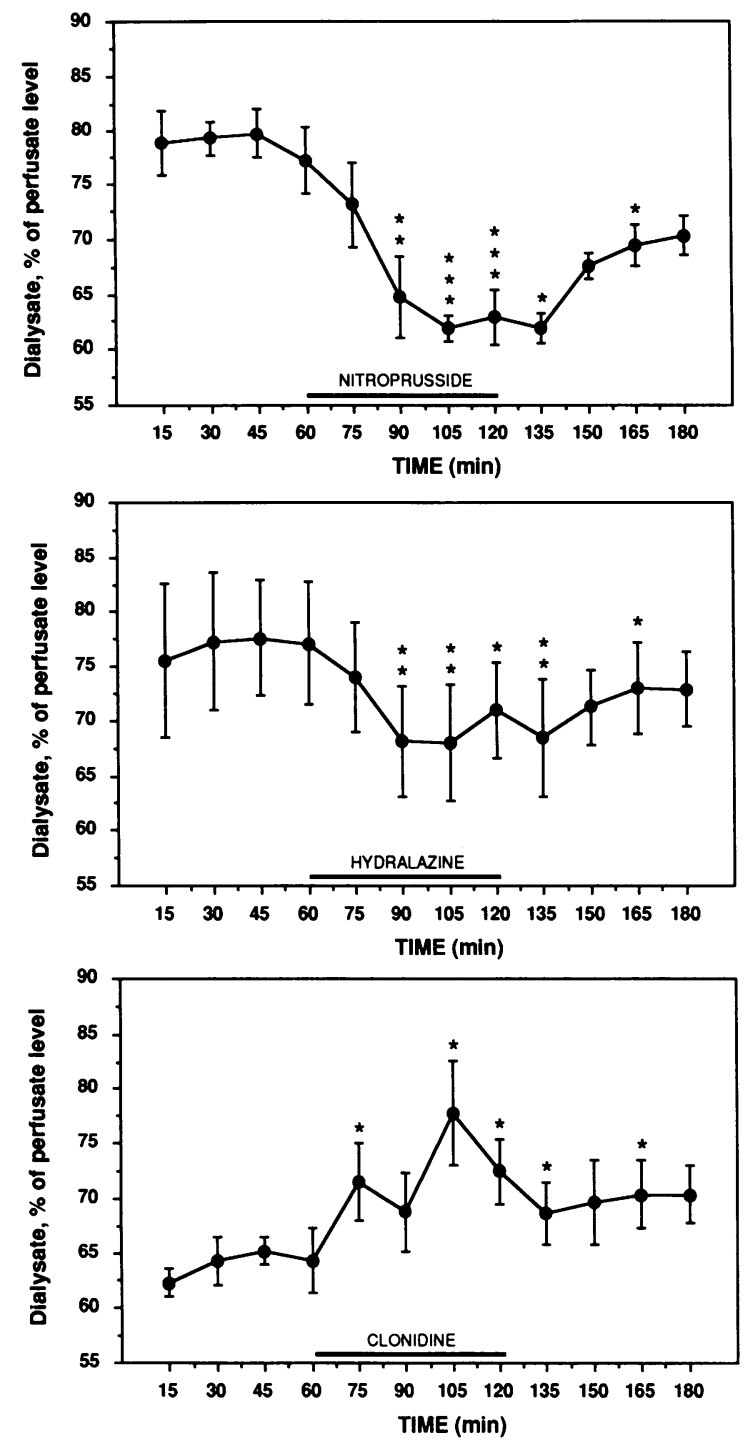

Figure 7. Effect of vasoactive drugs on the ethanol concentration during microdialysis. Abdominal subcutaneous adipose tissue was microdialyzed with Ringer's solution supplemented with $50.0 \mathrm{mmol} /$ liter of ethanol. Dialysate was collected at 15 -min intervals and analyzed for ethanol. After $60 \mathrm{~min}$, nitroprusside ( $1.25 \mathrm{~g} /$ liter, upper graph $)$, hydralazine $(0.125 \mathrm{~g} /$ liter, middle graph $)$ or clonidine $\left(10^{-10}\right.$ $\mathrm{mol} /$ liter, lower graph) were added during another $60 \mathrm{~min}$ (indicated with a line), whereafter the dialysis solvent was changed to a drug-free Ringer-ethanol solution for another $60 \mathrm{~min}$. The ratio in percentage of ethanol in dialysate vs. perfusate was determined. The following statistical comparisons were made using Student's paired $t$ test: 15 min predrug vs. $15 \mathrm{~min}$ drug, $30 \mathrm{~min}$ predrug vs. $30 \mathrm{~min}$ drug, and so on; $15 \mathrm{~min}$ drug vs. $15 \mathrm{~min}$ postdrug, $30 \mathrm{~min}$ drug vs. $30 \mathrm{~min}$ postdrug and so on. ${ }^{*}$ Values statistically different at $P<0.05,{ }^{* *}$ at $P$ $<0.01$ and ${ }^{* * *}$ at $P<0.001$ using Student's paired $t$ test. Values are mean \pm SEM of six experiments with nitroprusside, four experiments with hydralazine and four experiments with clonidine.

anol from the dialysis solvent into the interstitial water space in order to indirectly evaluate the microcirculation $(11,18,19)$.

Exposure of the extracellular space of the adipose tissue to a selective alpha- 2 agonist (clonidine) promoted a paradoxical increment of glycerol concentration in the dialysate. Further evidence for this adrenergic effect was provided when the physi- ological amine, epinephrine, was administered to tissue that was pretreated with the nonselective beta-antagonist (propranolol). The effect of epinephrine in these experiments cannot be explained by incomplete beta-blockade, because previous microdialysis experiments have shown that propranolol in this concentration ( $10^{-4} \mathrm{~mol} /$ liter $)$ completely blocks the beta-receptor-mediated effect of epinephrine (13). The pseudolipolytic effect of clonidine occurred in both men and women and was more pronounced in the gluteal than in the abdominal adipose tissue. These findings are opposed to the expected action for an alpha-2 adrenergic agonist on fat cells. In vitro studies in human isolated adipocytes have clearly assessed the antilipolytic potencies of the alpha-2 agonists (20-23). Moreover, binding studies and lipolysis measurements have shown that in subcutaneous fat deposits and particularly in the gluteal region, the alpha-2 adrenergic antilipolytic pathway was strongly operative; epinephrine responsiveness was preferentially antilipolytic in these fat cells (5). In gluteal as well as in the abdominal adipose tissue, alpha-2 adrenoceptor number was found to be predominant. Alpha-2 adrenoceptors were from 3- to 10-fold more numerous than the beta-adrenoceptors. Based on fat cell adrenoceptor function, one can expect that clonidine will act as an antilipolytic agent when infused in situ in subcutaneous adipose tissue. Surprisingly it was not the case except in the abdominal adipose tissue at the highest concentrations of clonidine. One interpretation of this finding is that the glycerol level in the interstitial space reflects not only production by fat cells but also removal by the microcirculation. The vascular bed of the adipose tissue contains both beta- and alpha- 2 adrenoceptors. The stimulation of vascular alpha- 2 adrenoceptors by clonidine probably promotes vasoconstriction. The latter may lead to accumulation of glycerol in the interstitial space due to decreased removal, although some other nonspecific actions can also be involved. Therefore pharmacological experiments were performed to delineate the putative components of the clonidine action.

In a first set of experiments the action of clonidine on glycerol in adipose tissue was evaluated with the selective beta-antagonists propranolol and the beta-1/beta- 2 /alpha- 1 adrenergic receptor antagonist labetalol to unmask a possible nonspecific effect of the alpha-2 agonist. Under these conditions the clonidine effect remained unchanged, which demonstrates that a nonselective stimulation of alpha- 1 or beta adrenoceptors was not involved in the paradoxical increment of the glycerol level induced by clonidine. However, the combination of yohimbine (specific alpha-2 antagonist) with propranolol abolished the clonidine-induced effect. Therefore it is obvious that the glycerol-increasing effect of clonidine was indeed mediated by alpha-2 adrenergic receptors.

Since the clonidine effect cannot be explained by stimulation of fat cell alpha- 2 adrenergic receptors, it could be due to a vasoconstrictive effect mediated by clonidine interaction with vascular alpha- 2 adrenoceptors. Previous studies on the distribution of alpha-adrenoceptor subtypes in different blood vessels indicated that alpha- 2 adrenoceptors are present in veins and arteries although they are relatively more abundant in the former vessels (24). Furthermore it is clear that stimulation of alpha-2 adrenoceptors can promote strong vasoconstriction in blood vessels (25). When administered peripherally, clonidine exerts a short-lasting hypertension due the activation of vascular extrasynaptic alpha-2-adrenoceptors followed by a sustained hypotension involving central and presynaptic alpha-2 
adrenoceptors (26). In addition, the experiments with ethanol clearly show that clonidine inhibits the escape of the alcohol from the dialysis solvent. This is strong, indirect evidence that clonidine causes vasoconstriction and thereby decreases blood flow in adipose tissue.

Since there is no available method to directly measure blood flow during microdialysis experiments, one way to assess a modification of vascular tone is the use of direct-acting vasodilator compounds such as hydralazine and nitroprusside. When these agents were infused into adipose tissue by microdialysis it was shown that neither hydralazine or nitroprusside had significant effects when administered alone. However, both agents were able to counteract the increasing effect of the alpha-2 agonist on glycerol concentration in the dialysate. In the presence of hydralazine, clonidine caused a dose-dependent antilipolytic effect at low as well as high agonist concentrations. Furthermore, both hydralazine and nitroprusside accelerated the escape of ethanol from the dialysis solvent, indicative of vasodilation and stimulation of blood flow. We therefore propose that activation of vascular adrenoceptors by clonidine during microdialysis leads to a local vasoconstriction and therefore to an increase in extracellular glycerol with a concomitant decrease in the adipose tissue drainage. Previous data have demonstrated that human adipose tissue blood flow is subjected to autoregulation $(27,28)$ and that glycerol output, measured in venous blood, was impaired just after rising, whereas vascular resistance was increased $(7,29)$. This effect was reversed when the subject went back in the supine position. Thus, present and previous results suggest that local vasoconstriction can promote transitory sequestration of lipolysis metabolites in the adipose tissue extracellular space.

During lipolysis free fatty acids and glycerol are mobilized from fat cells after hydrolysis of triglycerides. According to a recent review free fatty acids may be even more sensitive than glycerol to change in blood flow (30). Glycerol is water soluble and can therefore move freely in the extracellular space. Free fatty acids, however, are water insoluble and must be bound to carrier proteins in order to move in the intracellular space. One might therefore anticipate that free fatty acids newly released from fat cells would have a longer residence tissue than glycerol in the interstitium surrounding the adipocytes. Thus, the importance of alpha-2 adrenoceptor-mediated vasoconstriction may be much greater for mobilization of free fatty acid than glycerol.

It is well established that sex and site influence the metabolic activity of adipose tissue. This can be of importance for regional differences between women and men in normal as well as excessive fat distribution. Although a clear sex difference was not demonstrated in clonidine effects, it appears that the glycerol increasing action of clonidine is significantly different between abdominal and gluteal adipose tissue. The latter data suggest that the vascular influence of alpha- 2 adrenoceptors on lipid mobilization is more pronounced in gluteal tissue. The first explanation of such a difference could be that the gluteal fat is more vascularized than the abdominal fat. The second hypothesis, which is more probable, could be that the vascular alpha-2 adrenergic tone is accentuated in gluteal tissue. However, the distribution and function of vascular adrenoceptors in different adipose localizations is unknown at present.

In summary, the present study shows that the in vivo regulation of lipid mobilization through adrenoceptors in adipose tissue is complex, involving a hitherto unrecognized role of vascular alpha-2 adrenoceptors. The local blood flow is an important parameter that must be considered in the adrenergic regulation of lipid mobilization from adipose tissue, since it may have paradoxical effects on the lipid content in the interstitial space of adipose tissue. The combination of fat cell antilipolysis and local vasoconstriction through alpha-2 adrenoceptors may be of great importance for inhibiting lipid mobilization from adipose tissue into the bloodstream under certain forms of sympathetic activation. The combined evaluation of adipose tissue blood flow and metabolism probably represents the best way to study lipolysis in situ with microdialysis.

\section{Acknowledgments}

The authors are grateful to Britt-Marie Leijonhufvud and Catharina Sjöberg for their valuable technical assistance in microdialysis experiments and to Eva Sjölin and Kerstin Wahlen for their excellent assistance and help in the glycerol bioluminescence measurements.

This study was supported by grants from the Swedish Medical Research Council, Karolinska Institute, Swedish Athletes' Research Council, Swedish Diabetes Association, Nordic Insulin Foundation and Swedish Tobacco Foundation.

\section{References}

1. Burns, T. W., P. E. Langley, B. E. Terry, D. B. Bylund, B. B. Hoffman, M. D. Tharp, R. J. Lef kowitz, J. A. Garcia-Sainz, and J. N. Fain. 1981. Pharmacological characterizations of adrenergic receptors in human adipocytes. J. Clin. Invest. 67:467-475.

2. Lafontan, M., and M. Berlan. 1981. Alpha adrenergic receptors and the regulation of lipolysis in adipose tissue. Trends Pharmacol. Sci. 2:126-129.

3. Fain, J. N., and J. A. Garcia-Sainz. 1983. Adrenergic regulation of adipocyte metabolism. J. Lipid Res. 24:945-986.

4. Lafontan, M., P. Mauriège, J. Galitzky, and M. Berlan. 1985. Adrenergic regulation of adipocyte metabolism. In International Symposium on Metabolic Complication of Human Obesities. J. Vague, P. Björntorp, and B. Guy-Grand, editors. Elsevier Science Publishers, Amsterdam. 161-172.

5. Mauriège, P., J. Galitzky, M. Berlan, and M. Lafontan. 1987. Heterogenous distribution of beta- and alpha2-adrenoceptor binding sites in human fat cell from various fat deposits: functional consequences. Eur. J. Clin. Invest. 17:156165.

6. Richelsen, B., S. B. Pedersen, T. Moller-Pedersen, and J. F. Bak. 1991. Regional differences in triglyceride breakdown in human adipose tissue: effects of catecholamines, insulin, and prostaglandin E2. Metab. Clin. Exp. 40:990-996.

7. Hjelmdahl, P., and B. Linde. 1985. Adrenergic control of blood flow and lipolysis in human adipose tissue. In Alpha-Adrenoceptor Blockers in Cardiovascular Disease. H. Refsum and O. D. Mjos, editors. Churchill Livingstone, Edinburgh. 151-164.

8. Arner, P., J. Bolinder, A. Eliasson, A. Lundin, and U. Ungerstedt. 1988. Microdialysis of adipose tissue and blood for in vivo lipolysis studies. Am. J. Physiol. 255:E737-E742.

9. Arner, P., E. Kriegholm, and P. Engfeldt. 1990. In situ studies of catecholamine-induced lipolysis in human adipose tissue using microdialysis. J. Pharmacol. Exp. Ther. 254:284-288.

10. Arner, P., E. Kriegholm, P. Engfeldt, and J. Bolinder. 1990. Adrenergic regulation of lipolysis in situ at rest and during exercise. J. Clin. Invest. 85:893898.

11. Hickner, R. C., H. Rosdahl, I. Borg, U. Ungerstedt, L. Jorfeldt, and J. Henriksson. 1991. Ethanol may be used with the microdialysis technique to monitor blood flow changes in skeletal muscle: dialysate glucose concentration is blood-flow dependent. Acta Physiol. Scand. 143:355-356.

12. Tossman, U., and U. Ungerstedt. 1986. Microdialysis in the study of extracellular levels of amino acids in the rat brain. Acta Physiol. Scand. 128:9-14.

13. Arner, P., E. Kriegholm, and P. Engfeldt. 1991. In vivo interactions between beta- 1 and beta- 2 adrenoceptors regulate catecholamine tachyphylaxia in human adipose tissue. J. Pharmacol. Exp. Ther. 259:317-322.

14. Bolinder, J., E. Hagstrom, U. Ungerstedt, and P. Arner. 1989. Microdialysis of subcutaneous adipose tissue in vivo for continuous glucose monitoring in man. Scand. J. Clin. Lab. Invest. 49:465-474.

15. Hellmer, J., P. Arner, and A. Lundin. 1989. Automatic luminometric kinetic assay of glycerol for lipolysis studies. Anal. Biochem. 177:132-137.

16. Lundin, A., J. Hellmer, and P. Arner. 1989. A new linear plot for standard 
curves in kinetic substrate assays extended above, the Michaelis-Menten constant: Application to a luminometric assay of glycerol. Anal. Biochem. 177:125131 .

17. Bernst, E., and I. Gutman. 1974. Determination of ethanol with alcohol deshydrogenase and NAD. In Methods of Enzymatic Analysis. H. U. Bergmeyer, editor. Verlag, Weinheim. 3:1499-1505.

18. Lönnroth, P., P. A. Jansson, and U. Smith. 1987. A microdialysis method allowing characterization of the intercellular water space in humans. Am. J. Phys iol. 253:E228-E231.

19. Jansson, P. A., U. Smith, and P. Lönnroth. 1990. Interstitial glycerol concentration measured by microdialysis in two subcutaneous regions in humans. Am. J. Physiol. 258:E918-E922.

20. Lafontan, M., and M. Berlan. Evidence for the $\alpha 2$-nature of the alphaadrenergic receptor inhibiting lipolysis in human fat cells. Eur. J. Pharmacol. 66:87-93.

21. Engfeldt, P., P. Arner, and J. Östman. 1983. Studies on the regulation of phosphodiesterase in human adipose tissue "in vitro." J. Clin. Endocrinol. Metab. 56:501-506.

22. Richelsen, B., and O. Pedersen. 1985. $\alpha 2$-Adrenergic binding and action in human adipocytes. Comparison between binding to plasma membrane preparations and to intact adipocytes. Eur. J. Pharmacol. 119:101-112.

23. Galitzky, J., M. Taouis, M. Berlan, D. Rivière, M. Garrigues, and M. Lafontan. 1988. $\alpha 2$-Antagonist compounds and lipid mobilization: evidence for a lipid mobilizing effect of oral yohimbine in healthy male volunteers. Eur. J. Clin. Invest. 18:587-594.

24. McGrath, J. C., C. M. Brown, and V. G. Wilson. 1989. Alpha-adrenoceptors: a critical review. Med. Res. Rev. 9:407-533.

25. McGrath, J. C., V. G. Wilson, W. R. Dunn, and A. G. B. Templeton. 1991. The interaction between $\alpha 1$ - and $\alpha 2$-adrenoceptors: the search for vascular $\alpha 2$-adrenoceptors in vitro. In Adrenoceptors: Structure, Mechanisms, Function. Advances in Pharmacological Sciences. E. Szabadi and C. M. Bradshaw, editors. Birkhäuser Verlag, Basel. 211-220.

26. Schmitt, H. 1977. The pharmacology of clonidine and related products. In Antihypertensive Agents. F. Gross, editor. Springer-Verlag, Berlin. 299-396.

27. Henricksen, O., S. L. Nielsen, and W. P. Paaske. 1973. Autoregulation of blood flow in human adipose tissue. Acta Physiol. Scand. 98:80-94.

28. Henricksen, O. 1977. Local sympathetic reflex mechanism in regulation of blood flow in human adipose tissue. Acta Physiol. Scand. 101:1-48.

29. Linde, B., and P. Hjemdahl. 1982. Effect of tilting on adipose tissue vascular resistance and sympathetic activity in humans. Am. J. Physiol. 242:H161H167.

30. Leibel, R. L., and N. K. Edens. 1990. Control of acyl glyceride in human adipose tissue: Reesterification and lipolysis. Comparability of in vivo and in vitro findings. In Obesity; Towards a Molecular Approach. G. A. Bray, D. Ricquier, and B. M. Spiegelman, editors. John Wiley \& Sons, Inc., New York. 189201. 